Análise da variabilidade espaço-temporal e identificação do padrão da precipitação na Bacia do Rio Tapacurá, Pernambuco Richarde Marques da Silva, Leonardo Pereira e Silva, Suzana Maria Gico Lima Montenegro, Celso Augusto Guimarães Santos

\title{
ANÁLISE DA VARIABILIDADE ESPAÇO-TEMPORAL E IDENTIFICAÇÃO DO PADRÃO DA PRECIPITAÇÃO NA BACIA DO RIO TAPACURÁ, PERNAMBUCO
}

\section{Analysis of the space-time variability and identification of rainfall pattern within the Tapecurá River Basin, Pernambuco State}

\author{
Richarde Marques da Silva \\ Departamento de Geociências, Universidade Federal da Paraíba \\ João Pessoa/PB - Brasil \\ richarde@geociencias.ufpb.br \\ Leonardo Pereira e Silva
}

Departamento de Engenharia Civil/Laboratório de Hidráulica, Universidade Federal de Pernambuco Recife/PE - Brasil lpsjampa@yahoo.com.br

Suzana Maria Gico Lima Montenegro Departamento de Engenharia Civil/Laboratório de Hidráulica, Universidade Federal de Pernambuco Recife/PE - Brasil suzanam@ufpe.br

Celso Augusto Guimarães Santos Departamento de Engenharia Civil e Ambiental, Universidade Federal da Paraíba João Pessoa/PB - Brasil celso@ct.ufpb.br

Artigo recebido para publicação em 28/02/2010 e aceito para publicação em 01/06/2010

RESUMO: $\quad$ Este estudo avaliou a variação espaço-temporal da precipitação de 1970 a 2000, na Bacia do Rio Tapacurá, localizada no Estado de Pernambuco. Diversos parâmetros estatísticos foram utilizados para estudar a estrutura das séries de precipitação anual e mensal, tais como média, desvio padrão, desvio normalizado, linha de tendência e coeficiente de variação. O estudo em escala mensal mostrou que no período de março a julho ocorrem $60 \%$ da precipitação total anual, e que o período seco ocorre entre agosto e fevereiro. Na escala anual os resultados mostraram uma diminuição significativa das chuvas da ordem de -20\% em relação à média histórica. Sobre a variabilidade espacial, constatou-se que a precipitação decresce no sentido leste-oeste, e que os períodos com menor volume pluviométrico possuem os maiores coeficientes de variação.

Palavras-chave: Variabilidade espacial. Krigagem. Recursos hídricos. SIG. Nordeste.

ABSTRACT: $\quad$ The study aimed to evaluate the space-time variability of rainfall for the period 1970 2000 , in Tapacurá river basin, located in Pernambuco State. Many statistical parameters were used to analyze the monthly and annual rainfall, such as mean standard deviation, normalized deviation, fitted equation 
and coefficient of variability. The study showed a major concentration of rainfall between March and July, when $60 \%$ of annual rainfall occurred, and that the dry season occurred between August to February. The annual variability showed a significant decrease of the rainfall in order of -20\% compared to the mean rainfall. About rainfall spatial variability, it was verified that it decreases at the direction East-West, and that the periods with low rainfall depths have higher coefficient of variation.

Keywords: Spatial variability. Kriging. Water resources. GIS. Northeast.

\section{INTRODUÇÃO}

A precipitação de um modo geral caracterizase como o retorno ao solo, do vapor d'água que se condensou, e se transformou em gotas de dimensões suficientes para quebrar a força da gravidade. Essa água em trânsito entre a atmosfera e o solo, chamada precipitação, tem aparentemente um aspecto quantitativo para cada local, mas sua distribuição, durante o ciclo anual é irregular em todo o planeta (LIRA et al., 2006).

A região Nordeste do Brasil caracteriza-se pela irregularidade espacial e temporal da precipitação e dos processos de escoamento e erosão dos solos, como também pelo alto potencial para evaporação da água em função da enorme disponibilidade de energia solar e altas temperaturas durante todo o ano. Assim, a região Nordeste do Brasil é considerada como uma região anômala no que se refere à distribuição espacial e temporal da precipitação ao longo do ano (SOUZA et al., 1998). Esta característica da variabilidade da precipitação é apontada por Galvão et al. (2005) como um dos maiores desafios no campo da hidrologia.

Estudar a variabilidade da precipitação é atualmente um desafio na área de recursos hídricos, sobretudo devido à grande relevância sobre as implicações da disponibilidade hídrica em bacias hidrográficas, principalmente aquelas localizadas em áreas semiáridas ou de transição, como é o caso da Bacia do Rio Tapacurá. O clima é considerado como o elemento condicionador da dinâmica do meio ambiente, pois exerce influência direta tanto nos processos de ordem tanto física quanto biológica, assim como na sociedade de modo geral, constituindo-se, portanto, em um recurso essencial para a vida e para as atividades humanas.
O estudo do comportamento espacial de um determinado elemento climático, como é o caso da precipitação, é fundamental para o mapeamento de áreas de aptidão para agricultura, bem como para o planejamento das atividades agrícolas e, sobretudo para o gerenciamento dos recursos hídricos. A identificação de regiões homogêneas quanto aos padrões individual ou combinado de diferentes elementos meteorológicos tem sido uma prática habitual e desenvolvida por diferentes metodologias, seja pelo uso de técnicas de análise multivariada ou por geoestatística, com o auxílio de Sistemas de Informações Geográficas. Simões e Bernardes (2008) apresentaram exemplos de estudos sobre análise espacial de elementos do meio físico e sua influência no comportamento da precipitação, utilizando ferramentas de estatística e de SIG, para obtenção do mapa de capacidade de infiltração para bacias do Estado de São Paulo.

Como exemplo de trabalhos que analisaram a distribuição espacial e temporal da precipitação, pode-se citar os estudos de Nery et al. (1998), que estudaram a pluviometria dos Estados de Alagoas, Pernambuco e Sergipe, e correlacioná-lo com seus atributos físicos, agrupando-os, utilizando análise multivariada para gerar os grupos homogêneos.

Andrade et al. (1999) apresentaram diagnóstico da precipitação mensal e anual para a Região Sul do Brasil, utilizando 14 séries de Santa Catarina, 8 do Paraná e 4 do Rio Grande do Sul, no período entre 1957 e 1997. Diversos parâmetros estatísticos foram utilizados para estudar a estrutura das séries de precipitação. Por meio da média, desvio-padrão e coeficiente de variação, foi possível detectar processos determinísticos bem marcados nas séries no período estudado. Alguns resultados mostraram uma grande variabilidade da precipitação, com diferentes dinâmicas explicando esta variabilidade na região. 
Análise da variabilidade espaço-temporal e identificação do padrão da precipitação na Bacia do Rio Tapacurá, Pernambuco Richarde Marques da Silva, Leonardo Pereira e Silva, Suzana Maria Gico Lima Montenegro, Celso Augusto Guimarães Santos

Sousa e Nery (2002) analisaram a variabilidade anual e interanual da precipitação e do déficit hídrico da região de Manuel Ribas, Estado do Paraná, no período de 1966 a 1997, com o intuito de caracterizála e dar subsídios ao melhor aproveitamento agrícola desenvolvido na Reserva Indígena Ivaí. Encontraram uma significativa variabilidade interanual da precipitação pluviométrica, principalmente em anos de eventos El Niño e La Niña.

Keller et al. (2005) usaram a técnica de análise hierárquica de agrupamento com o objetivo de delimitar regiões homogêneas no Brasil, utilizando como variáveis de análise a distribuição temporal de períodos de secas e distribuições de frequência de precipitação. Os resultados permitiram identificar 25 zonas pluviometricamente homogêneas em todo o território brasileiro, contribuindo para estudos de riscos climáticos na agricultura.

Nery e Alves (2009) analisaram a variabilidade da precipitação pluvial da Unidade de Gerenciamento de Recursos Hídricos do Médio Paranapanema, tanto espacial quanto temporalmente. Para tanto, foram utilizadas técnicas de estatística básica e de geotecnologias para as 33 séries pluviométricas, no período de 1940 a 2000. Mais recentemente, estudos vêm sendo realizados para se observar os efeitos da distribuição espacial da precipitação diária sobre a umidade do solo, o nível de água subterrânea (SCHUURMANS; BIERKENS, 2007), sua influência no escoamento superficial (FAURÈS et al., 1995) e na produção de sedimentos em escala de bacia hidrográfica (MELLO et al., 2006).

Devido a dificuldade de obtenção de dados pluviométricos e uma série histórica mais representativa para estudos mais consistentes, muitas vezes é utilizada uma única estação de dados em uma bacia e se considera que a precipitação é homogênea em toda a bacia. Em outros casos, se utiliza dados pluviométricos de estações fora dos limites da área de estudo. Para uma modelagem de variabilidade mais aprofundada é importante ter mais de um posto de coleta de dados na área e com a maior quantidade possível de dados. Nesse contexto, o objetivo deste trabalho foi analisar a variabilidade temporal e espacial da precipitação sobre a Bacia do Rio Tapacurá, a partir de parâmetros estatísticos e o auxílio de Sistemas de Informação Geográfica.

\section{MATERIAL E MÉTODOS}

A Bacia do Rio Tapacurá possui uma área de drenagem de aproximadamente $480 \mathrm{~km}^{2}$, e está localizada entre as coordenadas $230000 \mathrm{mE}, 270000 \mathrm{mE}$, e $9090000 \mathrm{mN}, 9120000 \mathrm{mN}$, dentro da Bacia do Rio Capibaribe, Estado de Pernambuco, Brasil (FIGURA 1).

O clima da região é do tipo As', clima quente e úmido do tipo tropical na classificação climática de Köeppen. A temperatura mensal média oscila entre 23 e $27^{\circ} \mathrm{C}$, enquanto a umidade relativa do ar, durante os meses de março a julho, é superior a 70\%. O relevo da Bacia do Rio Tapacurá é representado por morros de declividade elevada, tendo seu ponto mais alto situado na cota de $645 \mathrm{~m}$ e o ponto mais baixo no seu exutório, com 40 m (SILVA et al., 2008).

O relevo da Bacia do Rio Tapacurá em sua maior parte é constituído por morros e cristas, elaborados em estruturas cristalinas do Núcleo Nordestino do Escudo Brasileiro. Os morros predominam na terça parte oriental da bacia. Ocorrem, sobretudo, ao longo da calha do Rio Tapacurá, contornando a estreita várzea aluvial (BRAGA, 2001).

A FIGURA 1 mostra também a localização geográfica dos postos utilizados no estudo e o modelo de elevação digital da bacia. Foram utilizados dados das médias mensais do período de 1970 a 2000 de dez postos pluviométricos, dos quais seis sob responsabilidade da Agência Nacional das Águas (ANA) e quatro do Laboratório de Meteorologia do Estado de Pernambuco (LAMEPE). A TABELA 1 apresenta informações dos postos utilizados neste trabalho. A TABELA 2 mostra a descrição dos períodos de falhas das estações pluviométricas utilizadas neste estudo entre o período de 1970 a 2000.

No que tange o preenchimento de falhas podese ressaltar que esse procedimento só foi utilizado nos postos sob responsabilidade do LAMEPE, uma vez que os mesmos não possuíam dados consistidos. Diferentemente dos dados obtidos junto aos postos da ANA, que já possuem as falhas preenchidas. Assim, os demais postos de Vitória de Santo Antão, Nossa Senhora da Luz, Russinha, Engenho Bela Rosa, Apoti (Duarte Dias), Usina Tiuma, possuem dados consistidos e já com preenchimento de falhas realizado.

Para o preenchimento de falhas mensais dos 


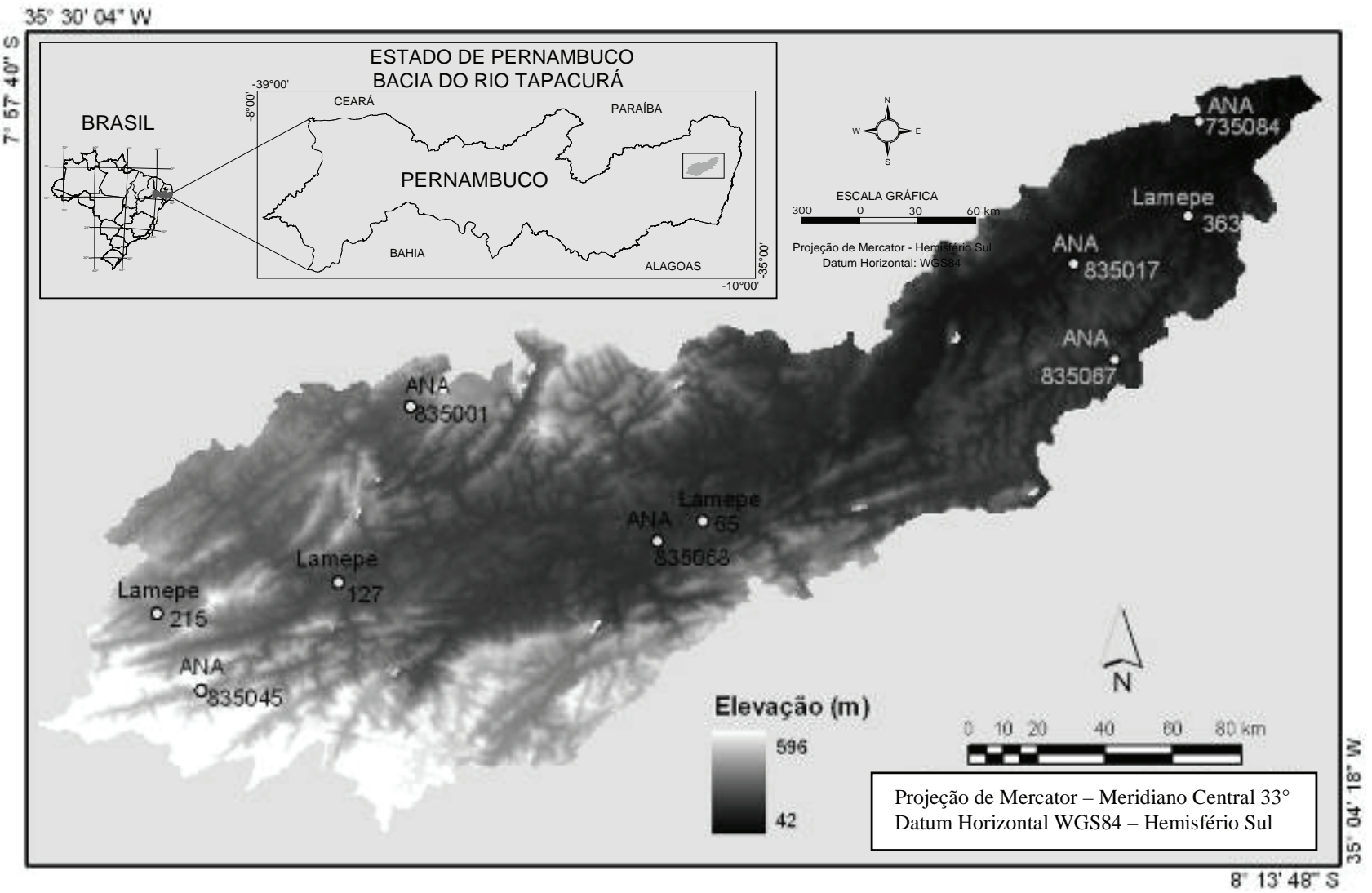

FIGURA 1: Localização geográfica dos postos pluviométricos utilizados e modelo digital de elevação da Bacia do Rio Tapacurá.

TABELA 1: Descrição das estações pluviométricas utilizadas.

\begin{tabular}{cccccc}
\hline Código & Posto & Operador & Latitude & Longitude & $\begin{array}{c}\text { Elevação } \\
(\mathrm{m})\end{array}$ \\
\hline 835068 & Vitória de Santo Antão & ANA & $-8,126$ & $-35,295$ & 154 \\
835067 & Nossa Senhora da Luz & ANA & $-8,067$ & $-35,144$ & 116 \\
835045 & Russinha & ANA & $-8,175$ & $-35,445$ & 338 \\
835017 & Engenho Bela Rosa & ANA & $-8,036$ & $-35,158$ & 78 \\
835001 & Apoti (Duarte Dias) & ANA & $-8,082$ & $-35,376$ & 243 \\
735084 & Usina Tiuma & ANA & $-7,989$ & $-35,117$ & 105 \\
65 & Vitória de Santo Antão & LAMEPE & $-8,120$ & $-35,280$ & 166 \\
127 & Pombos & LAMEPE & 8,140 & $-35,400$ & 386 \\
215 & Gravatá & LAMEPE & $-8,150$ & $-35,460$ & 303 \\
363 & São Lourenço da Mata & LAMEPE & $-8,020$ & $-35,120$ & 92 \\
\hline
\end{tabular}

postos pluviométricos com falhas foi utilizado o método da ponderação regional (Equação 1):

$$
P_{x}=\frac{1}{3}\left(\frac{M_{x}}{M_{a}} P_{a}+\frac{M_{x}}{M_{b}} P_{b}+\frac{M_{x}}{M_{c}} P_{c}\right)
$$

sendo $P_{x}$ a variável que guardará os dados cor- rigidos, $M_{x}$ a média aritmética da estação com falha, $M_{a}, M_{b}$ e $M_{c}$ a média aritmética das estações vizinhas, e $P_{a}, P_{b}$ e $P_{c}$ são os dados das estações vizinhas ao posto com falha, do mesmo ano que utilizamos para preencher a falha.

O método da ponderação regional é geralmen- 
Análise da variabilidade espaço-temporal e identificação do padrão da precipitação na Bacia do Rio Tapacurá, Pernambuco Richarde Marques da Silva, Leonardo Pereira e Silva, Suzana Maria Gico Lima Montenegro, Celso Augusto Guimarães Santos

TABELA 2: Descrição dos períodos de falhas das estações pluviométricas entre 1970 e 2000.

\begin{tabular}{|c|c|c|c|c|}
\hline Cód. & Posto & $\begin{array}{l}\text { Núm. } \\
\text { Falhas }\end{array}$ & $\begin{array}{l}\% \text { de } \\
\text { Falhas }\end{array}$ & Período de Falhas \\
\hline 65 & $\begin{array}{c}\text { Vitória de S. } \\
\text { Antão }\end{array}$ & 22 & 6,1 & nov/76; mai/74; jun/91 a dez/92; nov/93 \\
\hline 127 & Pombos & 75 & 20,8 & $\begin{array}{c}\text { set/70 a fev/71; set/71 a jan/72; ago a dez/72; mai/76; dez/77; jan a } \\
\text { ago/78; jan/92 a fev/95; nov dez/95; jan fev mar/96; jan nov/97; dez/97; } \\
\text { fev/98; set nov/99 }\end{array}$ \\
\hline 215 & Gravatá & 126 & 35,0 & $\begin{array}{l}\text { out/70 a dez/70; ago/72; nov/73; dez/74; jan jun ago/75; dez/76; dez/77; } \\
\text { jul/80; jun/81; abr dez/83; set ou/85; out/87; set nov dez/89; jan/90 a } \\
\text { set/96; fev/97 a nov97; jan/00 a dez/00; }\end{array}$ \\
\hline 363 & São L. da Mata & 112 & 31,1 & $\begin{array}{l}\text { set a dez/70; jan fev/72; abr/73; set/74; jun jul/75; mai/83; abr/84; jul } \\
\text { ago/85; mar abr jun/86; mar abr/88; jan jun/90; ago/91; abr jun/92; jul } \\
\text { nov dez/00 }\end{array}$ \\
\hline
\end{tabular}

te utilizado para o preenchimento de séries mensais e anuais, onde as falhas de um posto são preenchidas através de uma ponderação com base nos dados de pelo menos três postos vizinhos, que devem ser de regiões climatológicas semelhantes a do posto em estudo e possuir uma série de dados de no mínimo 10 anos. Deve-se ressaltar que o uso do método de ponderação regional é uma técnica bastante utilizada para cobrir as falhas de dados, entretanto, pode mascarar a variabilidade da precipitação, dependendo do intervalo a ser parametrizado.

Para a análise da distribuição espacial da precipitação na bacia foi utilizado o método de interpolação, conhecido como Krigagem para determinar a média mensal, média anual, desvio padrão, coeficiente de variação, e as médias sazonais dos períodos seco e chuvoso. Este método foi escolhido por ser um dos mais eficientes e utilizados em estudos sobre interpolação de dados espaciais (MELLO et al., 2003; REMACRE et al., 2008). O estimador da krigagem é obtido, segundo Matheron (1963), conforme:

$$
Z^{*}\left(X_{0}\right)=\sum_{i=1}^{n} \lambda_{i} Z\left(X_{i}\right)
$$

onde $Z^{*}\left(X_{0}\right)$ é o atributo da variável estimado no ponto; $l_{i}$ são os ponderadores de krigagem; $Z(X)$ é o valor observado da variável $Z$ no i-ésimo ponto. Para a krigagem ser ordinária deve-se satisfazer a condição de que:

$$
\sum_{i=1}^{n} \lambda_{i}=1
$$

Os ponderadores são obtidos pela resolução de um sistema de equações lineares do tipo $A X=B$, denominado sistema de krigagem, que conforme Rocha et al. (2007) pode ser escrito como segue:

$$
\left[\begin{array}{cccc}
\gamma\left(x_{1} ; x_{1}\right) & \cdots & \gamma\left(x_{1} ; x_{n}\right) & 1 \\
\vdots & \ddots & \vdots & \vdots \\
\gamma\left(x_{n} ; x_{1}\right) & \cdots & \gamma\left(x_{n} ; x_{n}\right) & 1 \\
1 & \cdots & 1 & 0
\end{array}\right]\left[\begin{array}{c}
\lambda_{1} \\
\vdots \\
\lambda_{n} \\
\mu
\end{array}\right]=\left[\begin{array}{c}
\gamma\left(x_{1} ; x_{0}\right) \\
\vdots \\
\gamma\left(x_{n} ; x_{0}\right) \\
1
\end{array}\right]
$$

onde $y\left(x_{n} ; x_{n}\right)$ é a variância espacial da n-ésima amostra com relação a ela mesma; $\mu$ é o Multiplicador de Lagrange; e $y\left(x_{n} ; x_{0}\right)$ é a variância espacial entre a n-ésima amostra e o ponto $x_{0}$ que será estimado.

Quanto aos critérios para escolha das séries, considerou-se a distribuição temporal e espacial das estações representativas da região, apresentando 30 anos de dados, com o mínimo de dados faltantes. Em seguida, realizou-se a homogeneização dos dados de forma a originar séries totais anuais nos períodos estudados. Esta teve por objetivo estabelecer um controle das séries e foi realizada com valores acumulados que possibilitaram determinar a consistência dos dados coletados. Para tanto, elegeu-se uma série cujos 
dados apresentaram-se mais completos e, portanto, mais representativos, e que foi denominado a estação modelo, através do qual foram preenchidas as falhas de coleta de dados das estações mais próximas e mais semelhantes.

Com o propósito de se analisar a tendência de ocorrência histórica da variabilidade temporal da ocorrência de meses com anomalias, ou seja, acima ou abaixo da média histórica, foi analisado o cálculo da anomalia, para cada ano de todas as séries anuais, dentro do período estudado, obtido por:

$$
A=\left(x-x_{i}\right)
$$

sendo $A$ o valor total de precipitação do ano com anomalia, $x_{i}$ o valor anual total calculado, e $x$ o valor médio anual (média climatológica) do referido período. Em seguida, com base nos dados espacializados das médias mensais dos postos, foram traçadas em ambiente SIG todas as isoietas das análises estatísticas pelo método de interpolação Krigagem.

Para a avaliação das tendências da precipitação e suas respectivas retas de regressão, foram utilizados o desvio normalizado da precipitação e o método dos mínimos quadrados. De acordo com Moura et al. (1998) e Lira et al. (2006) o desvio normalizado da precipitação pode ser determinado pela seguinte relação:

$$
P_{n}=\left(\frac{X-\bar{X}}{\sigma}\right) \times\left(\frac{\sigma}{\bar{X}}\right)
$$

sendo $X$ o valor observado anual do posto pluviométrico, $\bar{X}$ a média histórica do mesmo posto analisado, e $\sigma$ o desvio padrão da série temporal.

Para o método dos mínimos quadrados foi definido um critério da "melhor reta de ajustamento" e da "melhor parábola de ajustamento", visando melhor adaptar o conjunto de dados. A reta de mínimo quadrado que se ajusta ao conjunto de pontos $\left(X_{1}, Y_{1}\right)$ $\left(X_{2}, Y_{2}\right), \ldots .,\left(X_{\mathrm{N}}, Y_{\mathrm{N}}\right)$ será representada pela equação de Spiegel (1961):

$$
Y=a_{0}+a_{1} X
$$

em que, as constantes $a 0$ e $a 1$ são determinadas mediante a resolução simultânea do sistema de equações abaixo, são denominadas equações da reta de mínimo quadrado.

$$
\begin{aligned}
& \Sigma Y=a_{0} N+a_{1} \Sigma X \\
& \Sigma X Y=a_{0} \Sigma X+a_{1} \Sigma X^{2}
\end{aligned}
$$

\section{RESULTADOS E DISCUSSÃO}

Na FIGURA 2, são analisadas as evoluções anuais da precipitação pluvial média para a Bacia do Rio Tapacurá. Pode-se observar a variabilidade nesta série, com destaque para o valor da precipitação máxima anual próxima de $2.000 \mathrm{~mm}$. Ainda de acordo com a FIGURA 2, em alguns anos, ocorreram precipitações significativamente acima da média, como em 1978, 1985 e 2000 (acima de 1.500 mm). Já as séries pluviométricas mínimas, ou seja, abaixo da média fo-

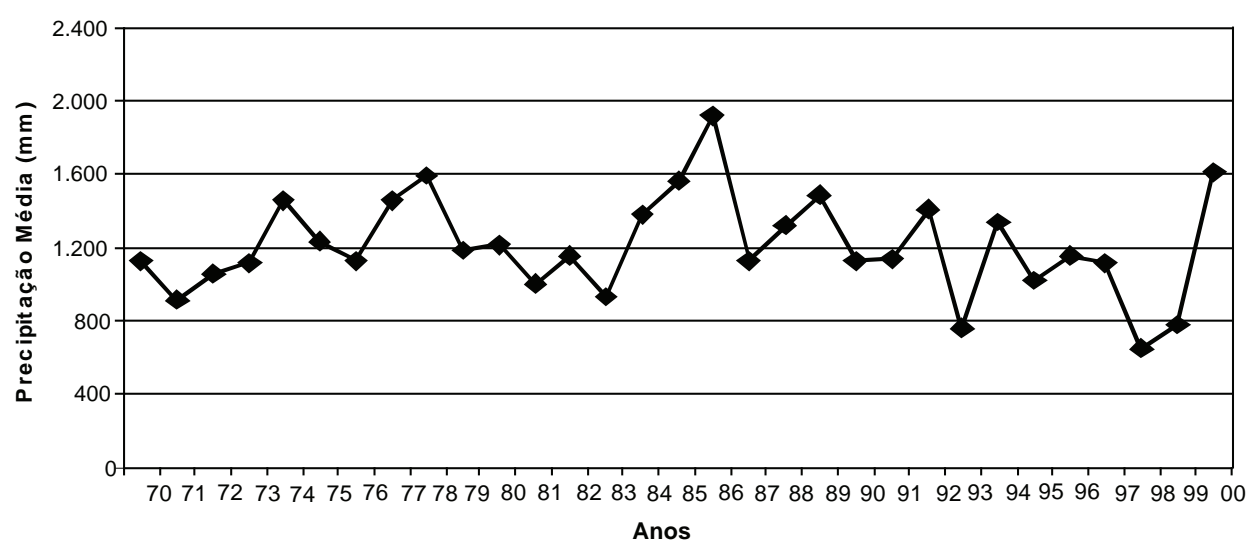

FIGURA 2: Evolução anual da precipitação média pluvial para a Bacia do Rio Tapacurá. 
Análise da variabilidade espaço-temporal e identificação do padrão da precipitação na Bacia do Rio Tapacurá, Pernambuco Richarde Marques da Silva, Leonardo Pereira e Silva, Suzana Maria Gico Lima Montenegro, Celso Augusto Guimarães Santos

ram registradas em torno de 700 a $1.000 \mathrm{~mm}$, com destaque para os anos de 1992, 1998 e 1999. Segundo Souza et al. (1998) e Andreoli e Kayano (2007) essas anomalias, isto é, a variabilidade anual e interanual podem ser explicadas no ponto de vista da climatologia como estando associados à influência dos eventos E1 Niño e La Niña, que influenciam na temperatura da superfície do mar.

Tanto o El Niño, a La Niña, como o gradiente inter-hemisférico de anomalias de temperatura da superfície do mar no Oceano Atlântico Tropical, são fatores importantes que modulam a precipitação na região Nordeste (NOBRE; SHUKLA, 1996). Isso tem motivado diversas pesquisas sobre as relações entre as temperaturas da superfície do mar dos Oceanos Pacífico e Atlântico e a precipitação na região Nordeste (NOBRE; SHUKLA, 1996; PEZZI; CAVALCANTI, 2001; KAYANO; ANDREOLI, 2004; GIANNINI, et al., 2004; KAYANO; ANDREOLI, 2007). A FIGURA 3 mostra a variabilidade anual do desvio normalizado e a linha de tendência da precipitação anual para a Bacia do Rio Tapacurá.

Pode-se observar que em 1978, 1985, 1986 e 2000 houveram desvios da precipitação normalizada acima de $20 \%$, sendo considerados anos muito chuvosos para a média histórica da região. Já os anos de 1971, 1981, 1983, 1993, 1998 e 1999 apresentaram desvios abaixo de $-30 \%$, sendo classificados como anos secos, com destaque para 1993 e 1998 com desvios negativos de $-60 \%$ e $-86 \%$, os quais podem ser considerados como extremamente secos. Estes resultados corroboram com os dados para outras regiões do Estado de Pernambuco encontrados por Lira et al. (2006), mostrando que essa tendência foi homogênea para toda a região. Percebe-se ainda na mesma figura que, de acordo com a linha de tendência da precipitação média obtida pelo cálculo do método dos mínimos quadrados, houve diminuição das chuvas da ordem de $-20 \%$ para o período estudado na região da Bacia do Rio Tapacurá.

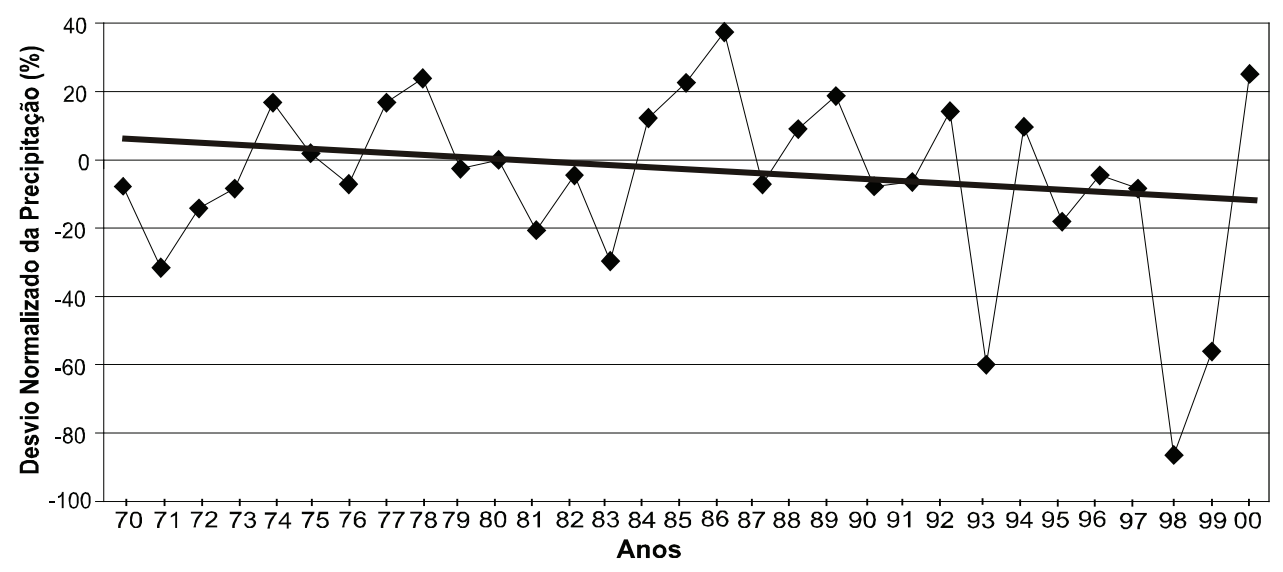

FIGURA 3: Desvio normalizado e linha de tendência da precipitação anual para a Bacia do Rio Tapacurá (Média anual: 1.210 mm; Desvio padrão: 372,50; CV: 0,31).

Os anos de 1998 e 1999 mostraram desvios de precipitação negativos, com redução das chuvas na ordem de $-86 \%$ e $-55 \%$, respectivamente. Segundo Diniz (1998) essa redução da precipitação nesse período foi mais presente no mês de junho em toda a costa leste; em julho mais a leste do Rio Grande do Norte e no nordeste da Bahia, sendo que Alagoas e Pernambuco ficaram ligeiramente com desvios positivos de precipitação. Para o mesmo ano, nos meses de agosto e setembro toda a costa teve desvio de precipitação negativo. Os maiores déficit de precipitação foram no leste do Rio Grande do Norte de 59\%; em Garanhuns$\mathrm{PE}$ as anomalias negativas de precipitação foram de $70 \%$. Houve algumas localidades onde a precipitação foi em torno do normal como no leste de Alagoas e em Sergipe, $70 \%$ do normal. A redução das chuvas nos quatro meses acumulados foi de $45 \%$ da normal no leste da região na distribuição espacial e temporal (DINIZ, 1998).

Na FIGURA 4, pode-se observar a variabilida- 
de pluvial anual na bacia em relação às anomalias. Dentro do período estudado, 13 anos possuíram precipitação pluvial acima da média, dos quais seis destes anos tiveram mais de $200 \mathrm{~mm}$ de precipitação média anual em relação à média histórica da bacia. No período estudado, 17 anos registraram precipitação média anual abaixo da média.

Nota-se ainda na FIGURA 4, que as anomalias negativas significativas estão marcadamente associadas aos anos 1971, 1972, 1980, 1982, 1992, 1998 e 1999. Já as anomalias marcadamente positivas estão presentes aos anos: 1974, 1977, 1978, 1984, 1986,
1989, 1992 e 2000, todas acima de $200 \mathrm{~mm}$. Deve-se ressaltar que a maioria desses anos com anomalias negativas da precipitação média anual está associada a eventos de El Nino (observar 1983/1985 e 1998/1999: eventos intensos) e La Niña (observar 1980/1982 e 1998/1999). Segundo Minuzzi et al. (2005), durante eventos do El Niño há a ocorrência de irregularidades na distribuição de chuvas, visto que estas tendem a ficar abaixo da média para a porção compreendida entre o nordeste do Estado de Minas Gerais até a porção leste da Região Nordeste.

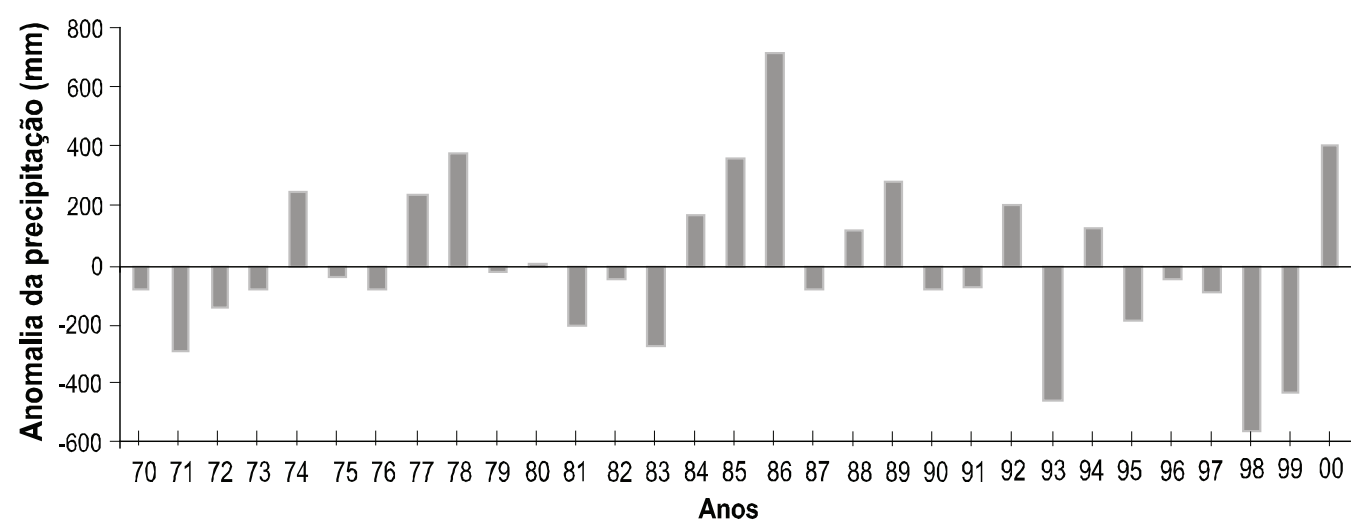

FIGURA 4: Anomalia das precipitações médias anuais (mm), para o período de 1970 a 2000.

O El Niño de 1983 foi considerado o evento extremo no século de um episódio quente. Entretanto, o El Niño de 1997 vem sendo considerado semelhante ao de 1983 pela sua intensidade. Nos meses e junho de 1983 toda a costa leste do Nordeste do Brasil apresentou desvios de precipitação negativos (RAO et al., 1986; LIMA, 1991).

A TABELA 3 apresenta a precipitação média anual para cada posto pluviométrico utilizado neste trabalho e o cálculo da precipitação média anual para a Bacia do Rio Tapacurá. Pode-se observar que a média da precipitação total anual para o período estudado, foi maior nos postos 835067 (Nossa Senhora da Luz), 363 (São Lourenço da Mata), e 835017 (Engenho Bela Rosa), respectivamente com valores acima da média da bacia (TABELA 3). Em contrapartida, nota-se que a média da precipitação total anual para o mesmo período, foi menor nos postos 127 (Pombos),
215 (Gravatá), 835001 (Apoti), e 835045 (Russinha), respectivamente com valores históricos abaixo da média (TABELA 3). Os demais postos: 65 (Vitória de Santo Antão), 735084 (Usina Tiuma), e 835068 (Vitória de Santo Antão), tiveram valores próximos da média anual da bacia.

Deve-se ressaltar que, em 13 anos ocorreram precipitação média anual acima da média, enquanto nos outros 17 anos ocorreram valores médios anuais de abaixo da média. Dos 13 anos com anomalias positivas, seis deles tiveram valores de precipitação na ordem de $200 \mathrm{~mm}$ acima da média histórica na bacia.

Na FIGURA 5, tem-se o cálculo da média da precipitação total anual para o período analisado. Pode-se observar que a média da precipitação total anual aumenta na direção de oeste para leste. De acordo com esta figura, observa-se variabilidade nos campos gerados de precipitação média anual, com valores de 
Análise da variabilidade espaço-temporal e identificação do padrão da precipitação na Bacia do Rio Tapacurá, Pernambuco Richarde Marques da Silva, Leonardo Pereira e Silva, Suzana Maria Gico Lima Montenegro, Celso Augusto Guimarães Santos

TABELA 3: Precipitação média anual (mm) para cada posto pluviométrico utilizado no estudo e precipitação média para a Bacia do Rio Tapacurá.

\begin{tabular}{|c|c|c|c|c|c|c|c|c|c|c|c|}
\hline \multirow{2}{*}{ Ano } & \multicolumn{10}{|c|}{ Precipitação nos Postos (mm) } & \multirow{2}{*}{$\begin{array}{l}\text { Média } \\
\text { Anual }\end{array}$} \\
\hline & 127 & 65 & 215 & 363 & 835001 & 835045 & 735084 & 835017 & 835068 & 835067 & \\
\hline 1970 & 1.093 & 973 & 794 & 1.097 & 957 & 811 & 1.195 & 1.411 & 1.283 & 1.648 & 1.126 \\
\hline 1971 & 593 & 833 & 652 & 1.184 & 704 & 787 & 873 & 1.124 & 1.213 & 1.209 & 917 \\
\hline 1972 & 862 & 810 & 730 & 1.279 & 819 & 888 & 1.179 & 1.425 & 1.038 & 1.558 & 1.059 \\
\hline 1973 & 822 & 901 & 691 & 1.425 & 869 & 758 & 1.176 & 1.384 & 1.222 & 1.935 & 1.118 \\
\hline 1974 & 1.162 & 1.240 & 1.048 & 2.076 & 1.135 & 1.199 & 1.625 & 1.891 & 1.513 & 1.703 & 1.459 \\
\hline 1975 & 1.006 & 1.331 & 906 & 1.404 & 1.055 & 999 & 1.452 & 1.508 & 1.071 & 1.637 & 1.237 \\
\hline 1976 & 933 & 1.143 & 754 & 1.500 & 835 & 875 & 1.293 & 1.361 & 1.021 & 1.565 & 1.128 \\
\hline 1977 & 1.185 & 1.658 & 799 & 1.810 & 1.131 & 1.128 & 1.547 & 1.810 & 1.436 & 2.042 & 1.455 \\
\hline 1978 & 1.105 & 1.706 & 1.241 & 1.998 & 1.214 & 1.285 & 1.629 & 1.998 & 1.310 & 2.430 & 1.592 \\
\hline 1979 & 809 & 1.430 & 805 & 1.402 & 852 & 935 & 1.361 & 1.401 & 922 & 1.912 & 1.183 \\
\hline 1980 & 1.028 & 1.589 & 733 & 1.500 & 1.068 & 880 & 1.067 & 1.496 & 827 & 1.933 & 1.212 \\
\hline 1981 & 749 & 1.291 & 714 & 1.223 & 759 & 908 & 1.019 & 1.223 & 755 & 1.370 & 1.001 \\
\hline 1982 & 894 & 1.442 & 620 & 1.584 & 764 & 823 & 1.241 & 1.583 & 790 & 1.856 & 1.160 \\
\hline 1983 & 727 & 1.183 & 605 & 1.204 & 664 & 692 & 1.036 & 1.140 & 730 & 1.333 & 931 \\
\hline 1984 & 1.073 & 1.726 & 912 & 1.746 & 1.093 & 1.000 & 1.422 & 1.729 & 1.087 & 1.976 & 1.376 \\
\hline 1985 & 1.345 & 1.638 & 1.199 & 2.311 & 1.325 & 1.288 & 1.371 & 1.925 & 1.483 & 1.804 & 1.569 \\
\hline 1986 & 1.279 & 2.170 & 1.103 & 3.733 & 1.424 & 1.303 & 1.767 & 2.437 & 1.486 & 2.557 & 1.926 \\
\hline 1987 & 764 & 1.248 & 475 & 2.300 & 799 & 777 & 1.063 & 1.384 & 882 & 1.625 & 1.132 \\
\hline 1988 & 1.013 & 1.686 & 734 & 1.924 & 1.039 & 937 & 1.361 & 1.568 & 1.317 & 1.684 & 1.326 \\
\hline 1989 & 1.015 & 1.835 & 1.038 & 2.038 & 1.188 & 1.151 & 1.483 & 1.998 & 1.321 & 1.832 & 1.490 \\
\hline 1990 & 695 & 1.410 & 734 & 1.615 & 885 & 837 & 1.092 & 1.527 & 995 & 1.462 & 1.125 \\
\hline 1991 & 735 & 1.214 & 758 & 1.990 & 926 & 830 & 1.083 & 1.524 & 856 & 1.467 & 1.138 \\
\hline 1992 & 944 & 1.292 & 917 & 2.668 & 1.067 & 1.036 & 1.351 & 1.770 & 1.258 & 1.831 & 1.413 \\
\hline 1993 & 485 & 506 & 471 & 1.844 & 564 & 535 & 697 & 921 & 608 & 945 & 758 \\
\hline 1994 & 995 & 1.389 & 967 & 1.708 & 1.089 & 1.065 & 1.389 & 1.692 & 1.210 & 1.883 & 1.339 \\
\hline 1995 & 729 & 1.133 & 740 & 1.233 & 837 & 818 & 1.067 & 1.301 & 930 & 1.447 & 1.024 \\
\hline 1996 & 696 & 888 & 779 & 1.495 & 1.011 & 989 & 1.290 & 1.571 & 1.124 & 1.748 & 1.159 \\
\hline 1997 & 294 & 913 & 860 & 1.499 & 994 & 972 & 1.268 & 1.545 & 1.105 & 1.719 & 1.117 \\
\hline 1998 & 294 & 438 & 227 & 903 & 606 & 592 & 773 & 941 & 673 & 1.047 & 649 \\
\hline 1999 & 473 & 708 & 262 & 1.033 & 692 & 676 & 882 & 1.075 & 768 & 1.195 & 776 \\
\hline 2000 & 1.230 & 1.445 & 1.149 & 2.028 & 1.342 & 1.312 & 1.711 & 2.085 & 1.491 & 2.320 & 1.611 \\
\hline Média & 872 & 1.264 & 788 & 1.702 & 958 & 938 & 1.250 & 1.540 & 1.088 & 1.699 & 1.210 \\
\hline
\end{tabular}

amplitudes de $800 \mathrm{~mm}$, a oeste, e $1.650 \mathrm{~mm}$, na parte leste da bacia, ou seja, valores duas vezes maiores. A dispersão dessa precipitação média total anual mostra valores maiores para a mesma região descrita acima sendo, portanto, uma região de maior precipitação média e também de maior variabilidade.

A distribuição espacial da chuva na bacia, pode ser atribuída a maior proximidade da parte leste da bacia em relação ao oceano. Outro fator preponderante que influencia na distribuição da precipitação é que a Bacia do Rio Tapacurá encontra-se localizada em uma zona de transição entre a Zona da Mata e o Agreste de
Pernambuco. Esta transição é claramente percebida pelos valores das isoietas, conforme a FIGURA 5. A Zona da Mata é uma sub-região litorânea da Região Nordeste que se estende do Rio Grande do Norte até o sul da Bahia, formada por uma estreita faixa de terra (cerca de $200 \mathrm{~km}$ de largura), que engloba a parte Oriental dos Estados do Rio Grande do Norte, Paraíba, Pernambuco e Bahia e o Centro-Leste de Sergipe e Alagoas. Toda essa região apresenta o período mais chuvoso no quadrimestre de abril a julho, correspondendo a aproximadamente $60 \%$ da precipitação anual (RAO et al., 1993). 


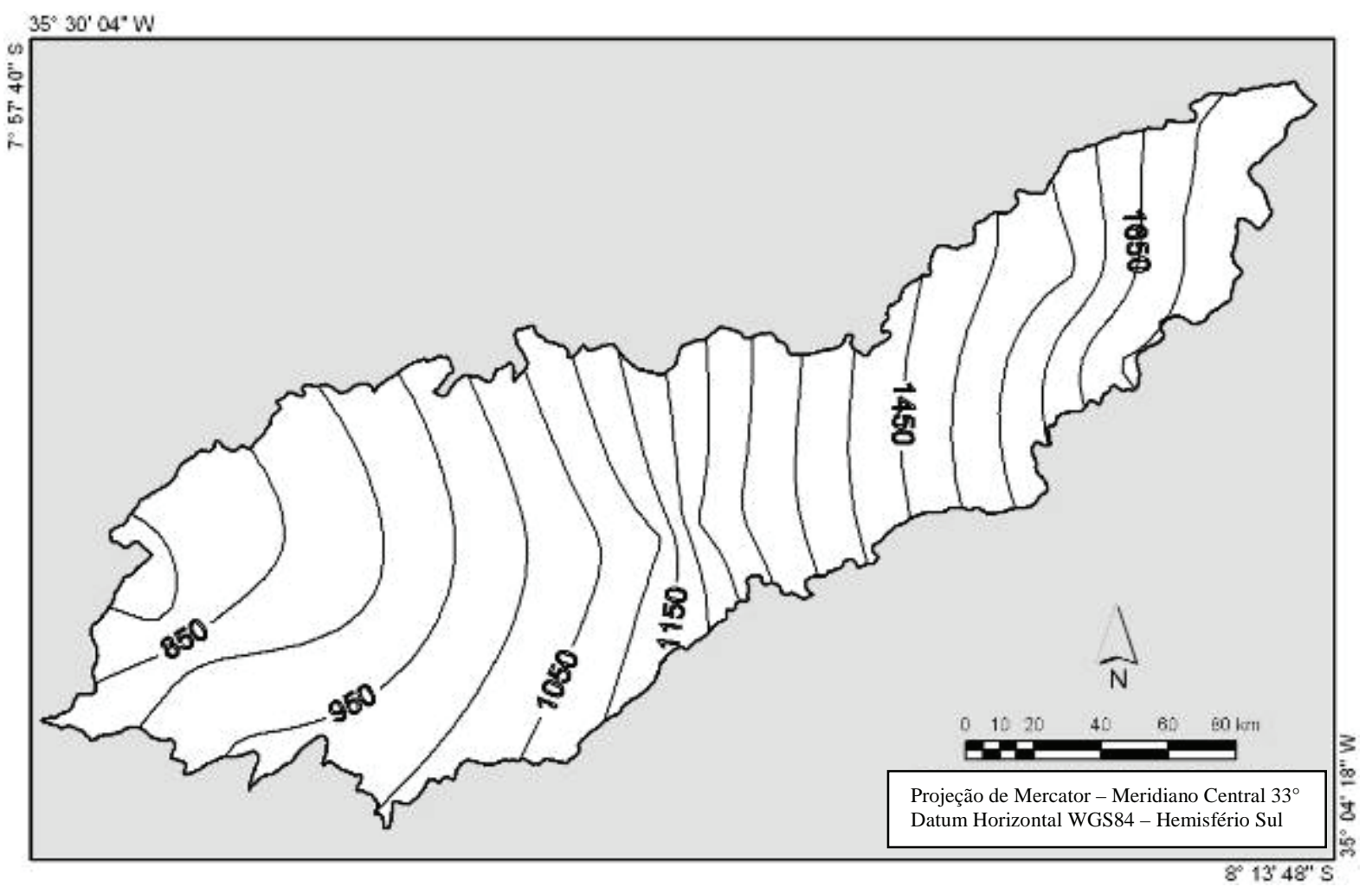

FIGURA 5: Média da precipitação total anual (mm), para a Bacia do Rio Tapacurá no período de 1970 a 2000.

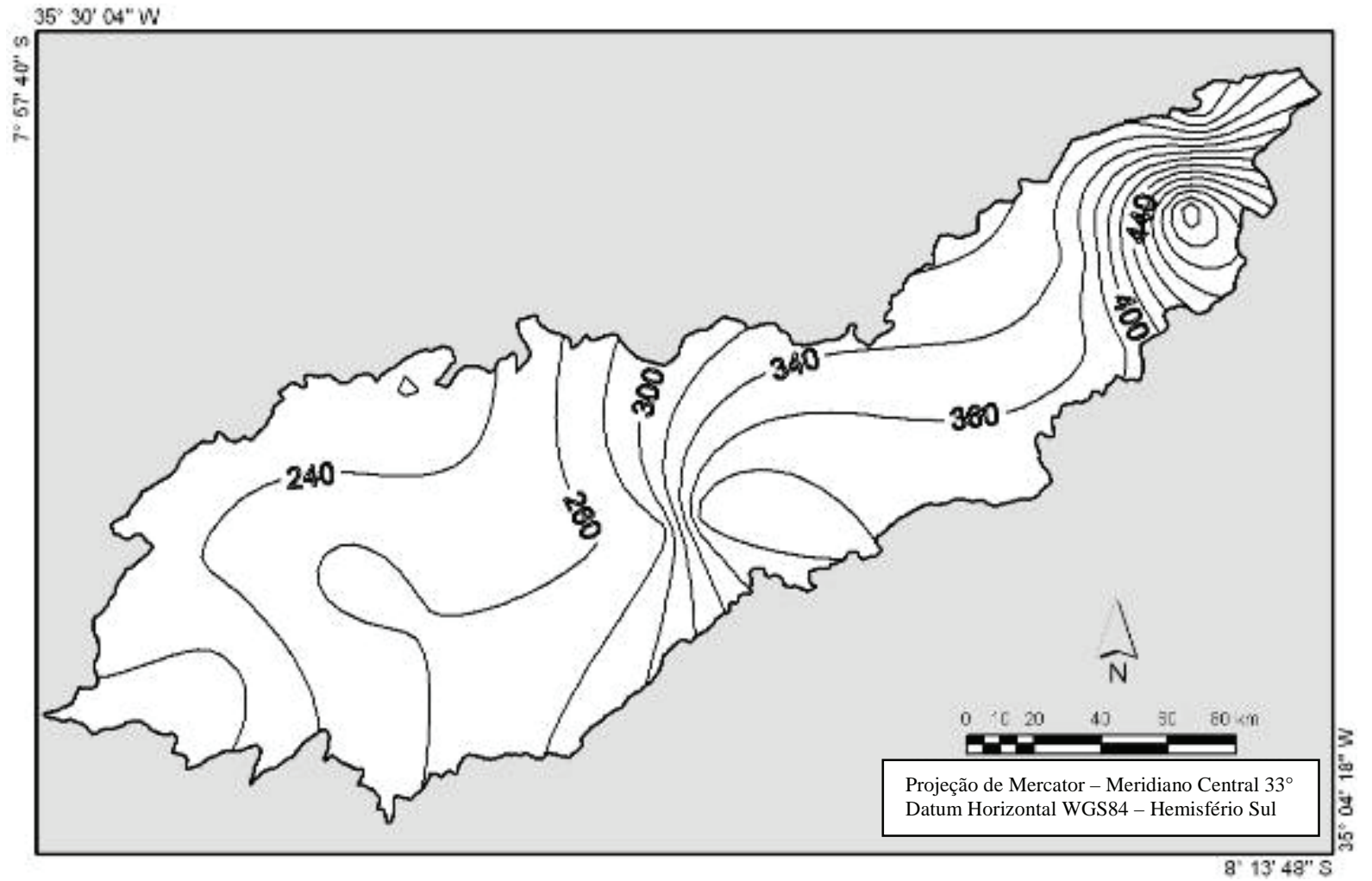

FIGURA 6: Desvio padrão da precipitação total anual, para a Bacia do Rio Tapacurá no período de 1970 a 2000. 
Análise da variabilidade espaço-temporal e identificação do padrão da precipitação na Bacia do Rio Tapacurá, Pernambuco Richarde Marques da Silva, Leonardo Pereira e Silva, Suzana Maria Gico Lima Montenegro, Celso Augusto Guimarães Santos

A FIGURA 6 apresenta o desvio padrão da precipitação total anual, para o período de 1970 a 2000 para a Bacia do Rio Tapacurá. A dispersão do desvio padrão da precipitação média anual mostra comportamento semelhante da distribuição espacial, com decréscimo dos valores no sentido leste-oeste, com desvio padrão mínimo e máximo de 220 e 520, respectivamente (FIGURA 6).

A maior heterogeneidade da distribuição da precipitação, sejam mais concentradas ou mais esparsas, gera maior impacto na paisagem. Os efeitos, por exemplo, da estiagem, especialmente as de grande magnitude, podem perdurar por muito tempo após o seu término, causando sérios problemas para as atividades agrícolas. Ademais, essa região possui grande relevância no que tange à agricultura, atividade econômica particularmente sensível às variações nas alturas e distribuição das precipitações e de outros parâmetros climáticos. Em contrapartida, o aumento da precipitação acarreta também sérios danos a própria agricultura e pode trazer aumento de problemas urbanos, como inundações, erosões e escorregamentos.
A FIGURA 7 mostra os valores do coeficiente de variação $(\mathrm{CV})$ para a Bacia do Rio Tapacurá. Nota-se que o período estudado é marcado por variabilidade moderada na região $(0,21-0,33)$. Os maiores valores de CV estão presentes na parte oeste da bacia, conforme os resultados da distribuição da precipitação média. Um dos fatores que pode-se atribuir é que a porção oeste da bacia apresenta as maiores elevações, fato este que pode ocasionar zonas de baixa precipitação em relação a outras.

A FIGURA 8 apresenta a evolução mensal da precipitação média pluvial para a Bacia do Rio Tapacurá entre 1970 e 2000. Pode-se observar que há uma onda anual marcada em todas as séries, com valores mínimos nos meses de agosto a fevereiro (período abaixo da média) e máximos de março a julho (período acima da média).

Observa-se que os meses de outubro e novembro são aqueles com menor precipitação observada, e julho, o mês de maior quantidade de chuva. Todas as séries apresentaram valores, no período úmido, entre 120 e 210 mm; já no período seco, a precipitação

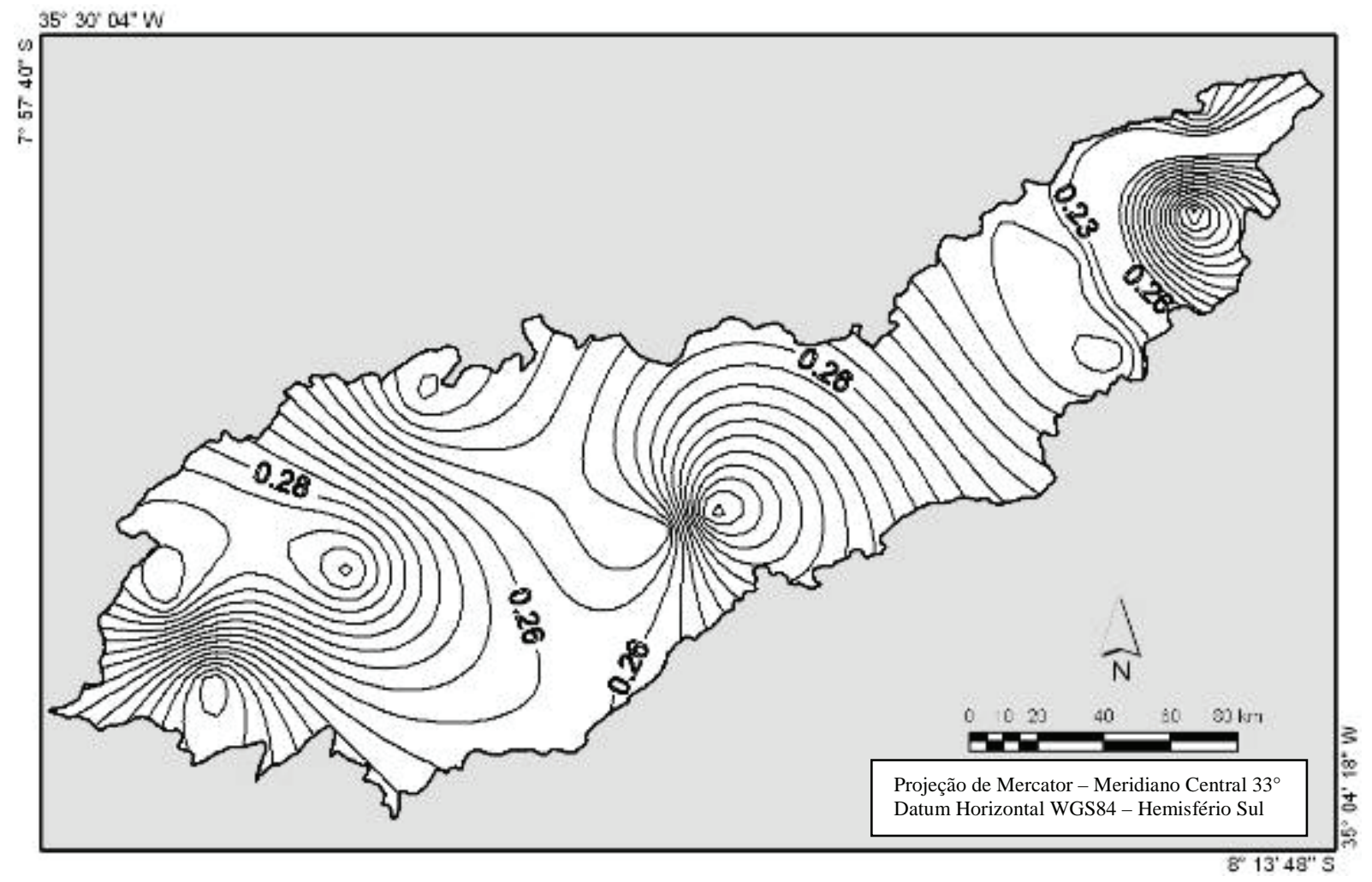

FIGURA 7: Coeficiente de variação da precipitação total anual, para a Bacia do Rio Tapacurá no período de 1970 a 2000. 


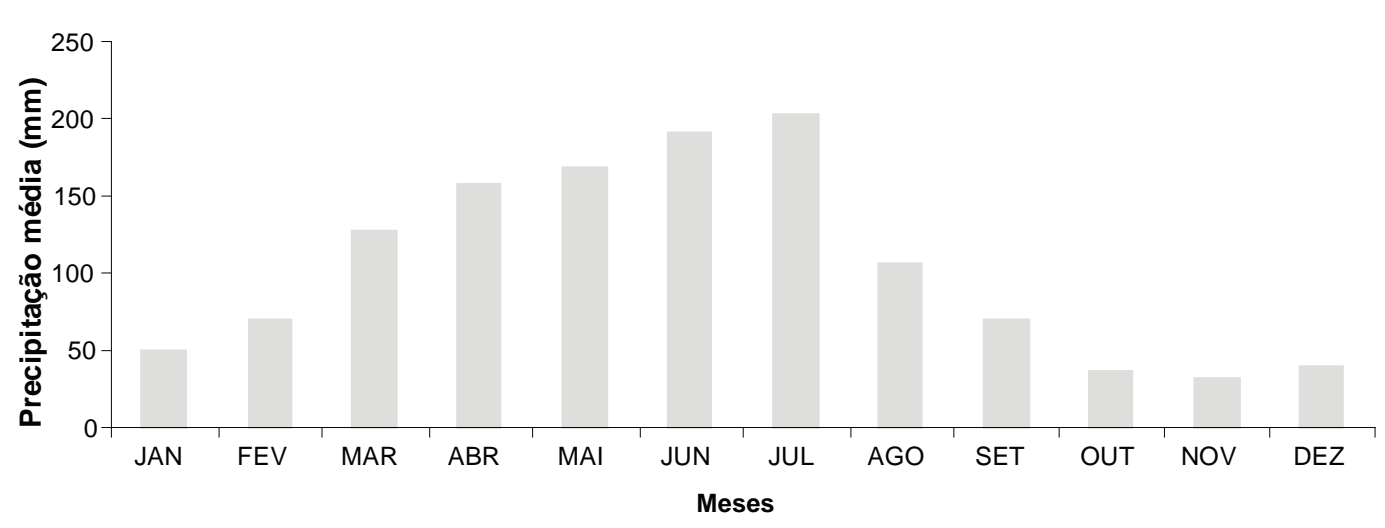

FIGURA 8: Evolução mensal da precipitação média pluvial (mm) para a Bacia do Rio Tapacurá no período de 1970 a 2000.

pluvial foi de, aproximadamente de 30 a $100 \mathrm{~mm}$, de acordo com os valores obtidos por Nery et al. (1998). Desta forma, separou-se os dados da precipitação em dois períodos distintos: considerou-se os meses de agosto, setembro, outubro, novembro, dezembro, janeiro e fevereiro (ASONDJF) como período seco, e os meses de março, abril, maio, junho e julho (MA-
MJJ) como período úmido (FIGURA 10). Pode-se observar que tanto em ASONDJF quanto em MAMJJ, o valor da precipitação é significativamente maior na região leste da bacia.

Na FIGURA 9 observa-se a análise do período seco (ASONDJF). As chuvas nesse período foram significativamente menores que no período úmido.

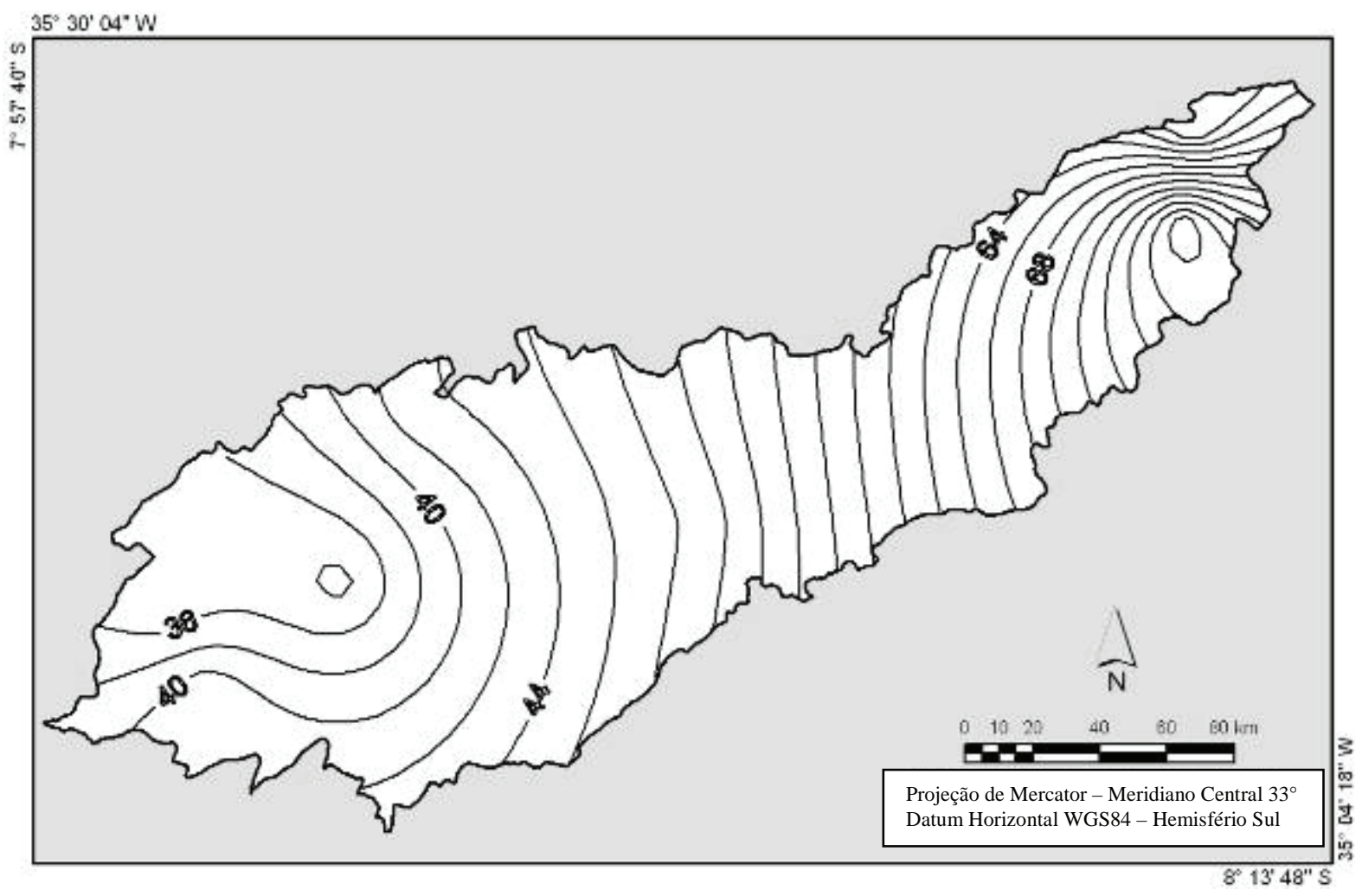

FIGURA 9: Variabilidade espacial da média de precipitação nos meses de agosto a fevereiro, para a Bacia do Rio Tapacurá no período de 1970 a 2000. 
Análise da variabilidade espaço-temporal e identificação do padrão da precipitação na Bacia do Rio Tapacurá, Pernambuco Richarde Marques da Silva, Leonardo Pereira e Silva, Suzana Maria Gico Lima Montenegro, Celso Augusto Guimarães Santos

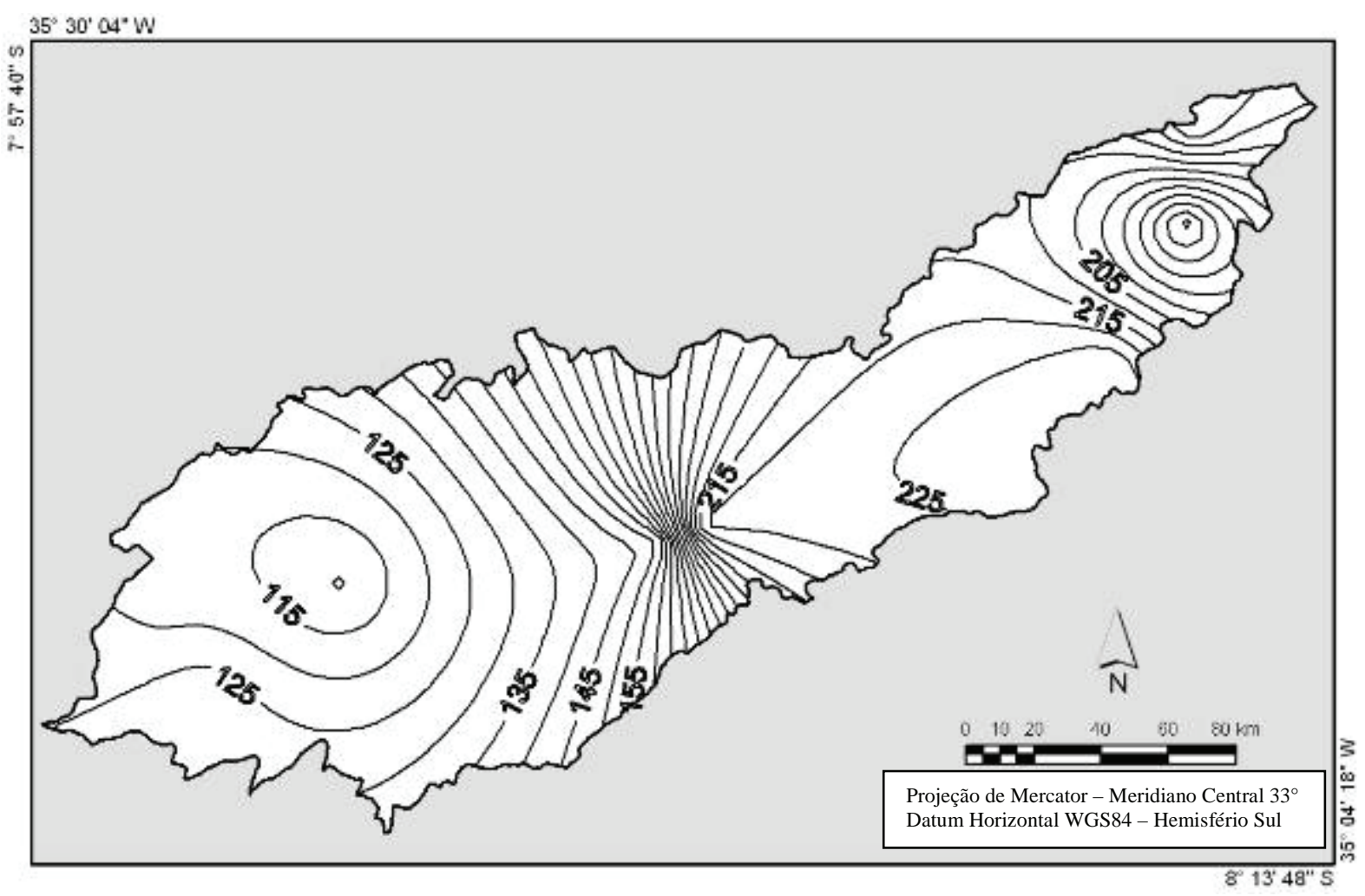

FIGURA 10: Variabilidade espacial da média de precipitação nos meses de março a julho, para a Bacia do Rio Tapacurá no período de 1970 a 2000.

As isolinhas traçadas são representativas para o período climatológico de utilizado neste trabalho (agosto, setembro, outubro, novembro, dezembro, janeiro e fevereiro). Constata-se que o valor mínimo para o período mais seco na região foi igual a $21 \mathrm{~mm} / \mathrm{mês}$ e o máximo de $64 \mathrm{~mm} / \mathrm{mês}$.

Na FIGURA 10, têm-se as isolinhas representativas do cálculo da média das chuvas no período chuvoso na bacia (MAMJJ). Comparativamente ao período seco, tem-se a maior concentração de chuva nesse período.

Segundo Nery e Alves (2009) é no período de verão que ocorrem as chuvas mais intensas, pela umidade proveniente da Amazônia, associada às frentes frias, provocando a intensificação de convecção profunda na região. Essas convecções geram nuvens cumulunimbus que são responsáveis por intensas chuvas, denominadas chuvas de verão. As Zonas de Convergência do Atlântico Sul, organizadas pelos sistemas frontais, são especialmente responsáveis pela maior intensidade das precipitações na área. Também pela maior incidência de radiação solar (verão no Hemisfério Sul), observam-se complexos convectivos, gerando intenso acúmulo de umidade nessa área e nesse período (RAO et al., 1986). Constata-se ainda que o valor mínimo da precipitação no período úmido obtido foi igual a $110 \mathrm{~mm} / \mathrm{mês}$ e o máximo de 230 $\mathrm{mm} / \mathrm{mês}$.

A costa litorânea do Nordeste do Brasil, particularmente a zona de transição entre a Zona da Mata e o Agreste, constitui-se numa região extremamente anômala no que tange a distribuição da precipitação, em relação a outras regiões localizadas nas mesmas latitudes, como é o caso da região Amazônica, como mostraram os resultados obtidos para a Bacia do Rio Tapacurá. Esse fato está fortemente relacionado às anomalias da temperatura da superfície do Oceano Atlântico Tropical (ANDREOLI et al., 2004).

Segundo Souza et al. (1998) e Andreoli et al. (2004) as anomalias de precipitação na região compreendida entre a zona costeira e o semiárido do Nordeste, de fato, estão fortemente relacionados pela 
influência direta da temperatura da superfície do Oceano Atlântico Tropical e pelas anomalias nos padrões atmosféricos. Para Andreoli e Kayano (2007) este dipolo associado às condições dinâmicas e termodinâmicas interfere sensivelmente na posição e intensidade da Zona de Convergência Intertropical (ZCIT) que, por sua vez, influencia a precipitação na região Nordeste.

\section{CONCLUSÕES}

Este trabalho analisou a variabilidade espaçotemporal da precipitação na Bacia do Rio Tapacurá mediante auxílio de Sistemas de Informação Geográfica e base de dados de precipitação de 10 postos pluviométricos, que foram utilizados para estimar as variabilidades mensais e anuais no período de 1970 a 2000.

Os resultados mostram grande variabilidade da precipitação anual na escala espacial com desvio padrão de 220 e 520 . Constatou-se uma grande variabilidade da precipitação de um ano para outro, com anos mais chuvosos: 1978, 1985 e 2000, e anos mais secos: 1992, 1998 e 1999. Os anos onde ocorreram precipitações significativamente acima da média foram e torno de $1.500 \mathrm{~mm}$, e os anos mais secos foram em torno de 700 a $1.000 \mathrm{~mm}$.

$\mathrm{Na}$ escala sazonal o período mais seco na bacia ocorre nos meses de agosto, setembro, outubro, novembro, dezembro, janeiro e fevereiro (30 a 100 $\mathrm{mm} / \mathrm{mês}$ ); e o período mais chuvoso ocorre nos meses de março, abril, maio, junho e julho (entre 120 e 210 $\mathrm{mm} / \mathrm{mês})$.

\section{AGRADECIMENTOS}

Os autores agradecem à FACEPE - Fundação de Amparo à Ciência e Tecnologia do Estado de Pernambuco, pela bolsa de doutorado do primeiro autor, ao CT-Hidro e o CNPq por apoiarem os projetos BEER-UFPE e MUCLIPE, com incentivos proporcionados através dos auxílios financeiros e de bolsas de pesquisa.

\section{REFERÊNCIAS}

ANDRADE, A. R.; BALDO, M. C.; NERY, J. T.
Variabilidade sazonal da precipitação pluviométrica de Santa Catarina. Acta Scientiarum. Maringá, PR. 21(4), p. 923-928, 1999.

ANDREOLI, R. V.; KAYANO, M. T. A importância relativa do atlântico tropical sul e pacífico leste na variabilidade de precipitação do Nordeste do Brasil. Revista Brasileira de Meteorologia, 22(1), p. 63-74, 2007.

ANDREOLI, R. V.; KAYANO, M. T.; GUEDES, R. L.; OYAMA, M. D.; ALVES, M. A. S. A influência da temperatura da superfície do mar dos oceanos pacífico e atlântico na variabilidade de precipitação em Fortaleza. Revista Brasileira de Meteorologia, 9(2), p. 113-122, 2004.

BRAGA, R. A. P. Gestão ambiental da Bacia do Rio Tapacurá - Plano de ação. Recife: Ed. Universitária da UFPE, 2001.

DINIZ, F. A. El niño e sua influência no período de inverno de 1997 em algumas regiões do Brasil. Bulletin Institute Français d études andines, 27(3), p. 771778, 1998.

FAURÈS, J. M.; GOODRICH, D. C.; WOOLHISER, D. A.; SOROOSHIAN, S. Impact of small-scale spatial rainfall variability on runoff modeling. Journal of Hydrology, 173, p. 309-326, 1995.

GALVÃO, C. O.; NOBRE, P.; BRAGA, A. C. F. M.; OLIVEIRA, K. F.; SILVA, R. M.; SILVA, S.R.; SANTOS, C. A. G.; GOMES FILHO, M. F.; LACERDA, F.; MONCUNILL, D. Climatic predictability, hydrology and water resources over Nordeste Brazil, IAHS Publ., 295, p. 211-220, 2005.

GIANNINI, A.; SARAVANAN, R.; CHANG, P. The preconditioning role of Tropical Atlantic Variability in the development of the ENSO teleconnection: implications for the prediction of Nordeste rainfall. Climate Dynamics, 22(6), p. 839-855, 2004.

KELLER, T.; ASSAD, E. D.; SCHUBNELL, P. R. Regiões pluviometricamente homogêneas no Brasil. Pesquisa Agropecuária Brasileira, 40(4), p. 311-322, 2005. 
Análise da variabilidade espaço-temporal e identificação do padrão da precipitação na Bacia do Rio Tapacurá, Pernambuco Richarde Marques da Silva, Leonardo Pereira e Silva, Suzana Maria Gico Lima Montenegro, Celso Augusto Guimarães Santos

LIMA, M. C. Variabilidade da precipitação no litoral leste da Região Nordeste do Brasil. 1991. 222p. Dissertação (Mestrado em Meteorologia) - Departamento de Meteorologia - São José dos Campos INPE; São José dos Campos-SP, 1991.

LIRA, M. L.; OLIVEIRA M.; DANTAS, R. T.; SOUZA, W. M. Alterações da precipitação em municípios do Estado de Pernambuco. Engenharia Ambiental, 3(1), p. 52-61, 2006.

MATHERON, G. Les principes de la geostatistique. CG, Ecole des Mines de Paris. Rapport N-88, 1963.

MELLO, C. R.; LIMA, J. M.; SILVA, A. M.; MELLO J. M.; OLIVEIRA, M. S. Krigagem e inverso do quadrado da distância para interpolação dos parâmetros da equação de chuvas intensas. Revista Brasileira de Ciência do Solo, 27(9), p. 925-933, 2003.

MELlO, G.; BUENO, C. R. P.; PEREIRA, G. T. Variabilidade espacial de perdas de solo, do potencial natural e risco de erosão em áreas intensamente cultivadas. Revista Brasileira de Engenharia Agrícola e Ambiental, 10(2), p. 315-322, 2006.

MINUZZI, R. B.; SEDIYAMA, G. C.; RIBEIRO, A.; COSTA, J. M. N. El Niño: ocorrência e duração dos veranicos do Estado de Minas Gerais. Revista Brasileira de Engenharia Agrícola e Ambiental, 9(3), p. 364-371, 2005.

MOURA, G. B. A.; SOUZA, I. A.; ARAGÃO, J. O. R.; PASSAVANTE, J. Z. O.; LACERDA, F. F.; RODRIGUES, R. S.; FERREIRA, M. A. F.; LACERDA, F. R. Estudo preliminar da variabilidade pluviométrica do setor leste do Nordeste do Brasil: parte I. In: X CONGRESSO BRASILEIRO DE METEOROLOGIA, 1998, Brasília-DF, Anais... Brasília-DF. CD ROM.

NERY, J. T.; ALVES, R. T. Variabilidade da precipitação pluvial na UGRH do Médio Paranapanema, Estado de São Paulo. Acta Scientiarum. 31(1), p. 93-102, 2009 .

NERY, J. T.; FACHINI, M. P.; TANAKA, L. K.,
PAIOLA, L. M., MARTINS, M. L. O. F.; BARRETO, L. E. G. S., TANAKA, I. Caracterização das precipitações pluviométricas mensais para os Estados de Alagoas, Pernambuco e Sergipe. Acta Scientiarum. 20(4), p. 515-522, 1998.

NOBRE, P.; SHUKLA J. Variations of sea surface temperature, wind stress, and rainfall over the Tropical Atlantic and South America. Journal of Climate, 9(19), p. 2464-2479, 1996.

PEZZI, L. P.; CAVALCANTI, I. F. A. The relative importance of ENSO and Tropical Atlantic sea surface temperature anomalies for seasonal precipitation over South America: a numerical study. Climate Dynamics, 17(2), p. 205-212, 2001.

RAO, V. B.; SATYAMURTY, P.; BRITO, J. I. B. On the 1993 drought in Northeast Brazil. International Journal of Climatology, 6(1), p. 43-51, 1986.

RAO, V. B.; LIMA, M. C.; FRANCHITO, S. H. Seasonal and interannual variations of rainfall over eastern Northeast Brazil. Journal of Climate, 6(9), p. 1754-1763, 1993.

REMACRE, A. Z.; NORMANDO, M. N.; SANCEVERO, S. S. Krigagem das proporções utilizando a krigagem da média: uma ferramenta auxiliar na modelagem de reservatórios. Revista Brasileira de Geociências, 38(1), p. 82-87, 2008.

ROCHA, M. M.; LOURENÇO, D. A.; LEITE, C. B. B. Aplicação de krigagem com correção do efeito de suavização em dados de potenciometria da cidade de Pereira Barreto-SP. Geologia USP, 7(2), p. 37-48, 2007.

SCHUURMANS, J. M.; BIERKENS, M. F. P. Effect of spatial distribution of daily rainfall on interior catchment response of a distributed hydrological model. Hydrology and Earth System Sciences, 11, p. 677-693, 2007.

SILVA R. M.; PAIVA, F. M. L.; MONTENEGRO, S. M. G. L.; FURTUNATO, O. M.; SANTOS, C. A. 
G. Comparação entre dois modelos de perdas de solo na Bacia Experimental do Rio Gameleira. In: VIII ENCONTRO NACIONAL DE ENGENHARIA DE SEDIMENTOS, 2008, Campo Grande-MS. Anais... Campo Grande-MS, 2008.

SIMÕES, S. J. C.; BERNARDES, G. P. Laboratório de Análise Geoespacial (LAGE): alguns exemplos de pesquisa em hidrologia em bacias hidrográficas. Revista Tecnologia, 29(1), p. 91-100, 2008.

SOUSA, P.; NERY, J. T. Análise da variabilidade anual e interanual da precipitação pluviométrica da região de Manuel Ribas, Estado do Paraná. Acta Scientiarum. 24(6), p. 1707-1713, 2002.

SOUZA, E. B.; ALVES, J. M. B.; NOBRE, P. Anomalias de precipitação nos setores norte e leste do nordeste brasileiro em associação aos eventos do padrão de dipolo observados na bacia do atlântico tropical. Revista Brasileira de Meteorologia, 13(2), p. 45-55, 1998.

SPIEGEL, M. R. Estatística. Rio de Janeiro: Sedegra Sociedade Editora e Gráfica LTDA, 1961. 